\title{
Saneamento Ambiental como Tema para Abordagem de Conceitos Químicos
}

\author{
Environmental Sanitation as a Theme for the Approach of Chemical \\ Concepts
}

Maria Cecília dos Santos Vieira'; Lenise Aparecida Martins Garcia².

1 Mestra em Ensino de Ciências, PPGEC/UnB, Brasília-DF, Brasil - mariaceciliavieira4@ gmail.com, /0000-0002-3475-5589

2 Doutora em Microbiologia e Imunologia, UnB, Brasília - DF, Brasil - lenise.garcia@ gmail.com, /0000-0002-7759-8608

Palavras-chave:

Aulas Temáticas.

Ensino de Química.

Formação Crítica.

\section{Keywords:}

Thematic Classes.

Chemistry Teaching.

Critical Formation.
RESUMO: As instituições de ensino são convidadas a refletir sobre as demandas sociais e discussões relacionadas ao ambiente e saúde, que estão sendo inseridas nesses espaços como temas promotores de diálogo. O saneamento ambiental caracteriza-se fundamentalmente como questão de saúde pública e isso o torna um tema de relevância social, que merece destaque no âmbito do ensino básico. Considerando que o tema possui o potencial de promover discussões contextualizadas, o presente artigo tem como objetivo apresentar a análise de uma proposta desenvolvida em uma escola pública localizada em Aparecida de GoiâniaGoiás, que envolveu a abordagem de conceitos químicos por meio do tema saneamento ambiental. Com o intuito de contribuir para a inserção do tema no ensino de química são apresentadas possibilidades de aulas temáticas baseadas na formação de uma consciência crítica e participativa dos estudantes frente às situações da contemporaneidade. A abordagem proporcionou a compreensão de conceitos e processos químicos envolvidos nos serviços relacionados ao saneamento ambiental como no tratamento de água e/ou esgoto, manejo e destinação final de resíduos sólidos. Possibilitou também o entendimento sobre a importância do saneamento e a atual situação tanto na esfera local quanto global, principalmente quando foram abordados o histórico, as ações e as consequências provocadas pela falta de saneamento no Brasil. Conclui-se que a inserção do tema pode contribuir para o reconhecimento da função social da química bem como à atribuição de significados no estudo de seus conceitos pela apresentação de aplicações na tecnologia e implicações socioambientais.

ABSTRACT: The educational institutions are invited to reflect on social demands and discussions related to the environment and health, which are being inserted in these spaces as themes that promote dialogue. Environmental sanitation is fundamentally a public health issue and this makes it a socially relevant issue that deserves to be highlighted in the context of basic education. Considering that the topic has the potential to promote contextualized discussions, this article aims to present the analysis of a proposal developed in a public school located in Aparecida de Goiânia-Goiás, which involved the approach of chemical concepts through the theme of environmental sanitation. In order to contribute to the insertion of the theme in the teaching of chemistry, possibilities of thematic classes based on the formation of a critical and participatory awareness of the students are presented. The approach provided an understanding of chemical concepts and processes involved in services related to environmental sanitation, such as water and / or sewage treatment, solid waste management and disposal. It also made it possible to understand the importance of sanitation and the current situation both locally and globally, especially when the history, actions and consequences of lack of sanitation in Brazil were addressed. It is concluded that the insertion of the theme can contribute to the 
recognition of the social function of chemistry as well as to the attribution of meanings in the study of its concepts through the presentation of applications in technology and social-environmental implications.

\section{INTRODUÇÃO}

As demandas geradas pelas sociedades se modificaram e intensificaram ao longo do tempo, mas ações visando à garantia da salubridade são observadas desde as civilizações antigas. As ações auxiliavam no afastamento do perigo representado pelas epidemias, que muitos dos povos antigos atribuíam à ira divina como punição pela ausência de cuidados com a higiene. Esta noção moveu grande parte das ações realizadas na Antiguidade, devido à inexistência de evidências que vinculassem a ausência de saneamento à ocorrência de doenças (REZENDE e HELLER, 2008).

Os povos passaram por um processo de adaptação aos costumes e necessidades de cada época e com isso aprimoraram o modo de pensar, avançando em termos de desenvolvimento da ciência e da tecnologia. Apesar dos avanços, alguns retrocessos também sobressaíram em função do modo utilitarista com que os bens naturais eram tratados, implicando em grandes impactos ambientais. No início da era industrial, de acordo com Branco (1972), foi indispensável a adoção de medidas para o afastamento dos resíduos. Com isso, surgiram sistemas de efluentes sanitários e industriais, cujo destino eram os rios, que começaram a sofrer os efeitos da poluição, tendo como consequência a mortandade de peixes e transmissão de doenças veiculadas pela água.

A Inglaterra foi um dos primeiros países a ser atingido principalmente por não dispor de rios volumosos e de grande extensão em sua região. Por esse motivo o país foi o primeiro a investir com o intuito de medir e caracterizar a poluição, regulamentar a proteção sanitária dos cursos d'água e desenvolver processos de tratamento de águas residuais. As iniciativas foram aos poucos sendo adotadas em outros países da Europa e América, conforme foram sendo industrializados (BRANCO, 1972).

$\mathrm{Na}$ Inglaterra, segundo Rocha (1997), também foram feitas pesquisas visando aperfeiçoar técnicas de tratamento de água de abastecimento. Identificaram no século XVIII a função coagulante do sulfato de alumínio, mas a utilização do produto começou somente no final do século XIX. Do mesmo modo aconteceu com o cloro e sua propriedade de oxidação da matéria orgânica presente na água, sendo descoberta na Suécia em 1774, mas o uso começou em 1830. Na época a existência de microrganismos havia sido identificada e o cloro passou a ser usado como desinfetante e bactericida nas Estações de Tratamento de Água.

Em 1912 foram realizadas as primeiras experiências com o processo químico que envolve cal-soda para a redução da dureza da água. A fluoretação, método utilizado no 
tratamento de água que consiste na adição de pequenas quantidades de flúor para prevenir cáries, começou a ser utilizada em meados de 1939. Sobre os processos de coagulação química e floculação, em 1954 os polieletrólitos tornaram-se conhecidos tanto nos Estados Unidos quanto na Europa (ROCHA, 1997).

Obviamente, em se tratando de saneamento, a atenção é voltada principalmente para a saúde pública. Mas segundo o Ministério das Cidades (2005), o agravamento de questões ambientais em nível mundial começou a chamar a atenção não só por causa do impacto no ambiente natural, mas também na saúde humana. Com isso surgiram movimentos em diferentes campos, dentre eles o do saneamento, que passou a incorporar, além das questões de ordem sanitária, as de ordem ambiental. Surgindo assim o conceito de saneamento ambiental, que abrange os serviços associados ao saneamento básico e os aspectos relacionados à poluição do ar e sonora, controle de vetores, entre outros (BRASIL, 2005).

Em suma as ações do saneamento ambiental, resumem-se em: I. Abastecimento de água dentro dos padrões de potabilidade vigentes; II. Esgotamento sanitário; III. Limpeza urbana e manejo de resíduos sólidos; IV. Manejo de águas pluviais; V. Controle ambiental de vetores e reservatórios de doenças; VI. Prevenção e controle de excesso de ruídos e emissões atmosféricas. De posse de informações sobre a função do saneamento ambiental é evidente a importância da efetivação dos serviços a ele relacionados para as cidades, implicando no bemestar da sociedade e ambiente.

\section{SANEAMENTO COMO TEMA MANIFESTO NO BRASIL}

As questões relacionadas ao saneamento ganharam destaque no Brasil e vários acontecimentos o levaram a se tornar um tema manifesto, dentre eles as epidemias de dengue, chikungunya e zika. O tema tornou-se motivo de diversas reportagens, manchetes de jornais e de pesquisas científicas. Silva, Morejon e Less (2014) fizeram um estudo com o intuito de traçar um panorama das condições de saneamento rural e urbano no Brasil, considerando os serviços de abastecimento de água, esgotamento sanitário e coleta de resíduos sólidos. Por meio do estudo os autores chegaram à conclusão de que as condições do saneamento brasileiro são precárias e que as pessoas são expostas diariamente a enfermidades provenientes da falta de acesso adequado aos serviços mencionados.

No ano de 2016, a campanha da fraternidade ecumênica da Igreja Católica abordou o direito dos cidadãos ao saneamento básico e debateu políticas públicas e ações que podem garantir a integridade e o futuro do meio ambiente. Com o tema "Casa comum, nossa responsabilidade" e o lema "Quero ver o direito brotar como fonte e correr a justiça qual 
Ensino, Saúde e Ambiente - V13 (1), pp. 326-343, Abr. 2020

riacho que não seca", a campanha ressalta o desenvolvimento da saúde integral e da qualidade de vida dos cidadãos (VERDÉLIO, 2016).

A revista "Em Discussão!" publica mensalmente os principais debates do Senado Federal. Em 2016, o saneamento ganhou destaque na revista mencionada no mês de maio, sendo que o tema havia sido eleito como objeto de exame por três vezes. Nas duas primeiras, evidenciou a destinação inadequada dos resíduos sólidos e na terceira, a crise de abastecimento de água. O tema voltou a ser discutido sob a justificativa de que o país se defronta com uma série de fragilidades em matéria de infraestrutura e comportamento evidenciados pela tríplice epidemia (dengue, chikungunya e zika) provocadas pelo mosquito Aedes aegypty.

A precariedade do saneamento cria ambientes propícios a outras doenças, além das transmitidas pelo Aedes aegypty, algumas são causadas pela ingestão de água contaminada ou pelo contato da pele ou mucosas com a própria água, lixo ou solo infectados. Grande parte dessas doenças possuem o ciclo de transmissão fecal-oral, ou seja, os agentes causadores presentes em fezes humanas ou animais são ingeridos, provocando a contaminação. Também ocorrem pela falta de cuidados com a higiene ou falta de destinação adequada dos resíduos sólidos (SENADO FEDERAL, 2016).

Para superar as dificuldades e alcançar a universalização dos serviços relacionados ao saneamento, de acordo com Rezende e Heller (2008), é necessária maior interação entre o operador dos serviços, o poder público e a população. Frente a gama de informações apresentadas e mesmo diante da pluralidade de fatores envolvidos, não é muito difícil relacionar a precariedade do saneamento com uma das mazelas que acometem a sociedade brasileira e esse é um dos motivos pelos quais atribuem sentido nas discussões sobre o referido tema também nas instituições de ensino.

\section{TEMA SANEAMENTO AMBIENTAL NO ENSINO}

As instituições de ensino são convidadas a refletir sobre as demandas sociais e o debate sobre o meio ambiente e saúde, que estão presentes nesse espaço como temas promotores de diálogo. Cada vez mais são estimuladas ações que consideram a relação dos temas ambientais com a qualidade de vida do homem e do planeta (PINHÃO e MARTINS, 2012). Partindo desse pressuposto, o saneamento sobressai como um tema de relevância social com potencial de promover discussões contextualizadas porque os serviços a ele relacionados ou a falta dele abarca a realidade das pessoas.

Trabalhos de cunho científico vêm sendo desenvolvidos sobre o ensino por meio de temas e uma parcela relaciona-se com o tema saneamento ambiental ou voltado para uma de 
suas ações. Em se tratando do ensino de química, Leal (2012) realizou um levantamento bibliográfico junto à revista "Química Nova" no período de 2000 a 2010 com o intuito de buscar uma caracterização da produção científica em aspectos que estivessem relacionados às questões do saneamento ambiental. Do quantitativo de 2.840 artigos, foram identificados 288 trabalhos que apresentaram alguma relação com o saneamento básico e/ou ambiental.

Os focos dos trabalhos identificados foram organizados em 10 temáticas provenientes do tema saneamento ambiental, sendo elas: análise de água, de esgoto e solo; agroquímicos; impacto ambiental; gerenciamento de resíduos; educação ambiental; monitoramento do ar, água e solo; monitoramento ambiental; o risco ambiental; tratamento; outros enquadrando a reciclagem, compostagem, resíduos sólidos, novos métodos de análise e polímeros biodegradáveis. A autora também analisou se os trabalhos apresentavam abordagem contextualizada e constatou que 148 artigos, correspondente a 51,4\% do total, não enfocaram apenas conhecimentos técnicos de química, apresentando uma relação contextualizada (LEAL, 2012).

Os dados evidenciam que o tema ou as temáticas elencadas, geralmente associadas aos serviços vinculados ao saneamento como processos químicos envolvidos no tratamento de água, tratamento de esgoto, manejo de resíduos sólidos e de águas pluviais, tem sido discutido e explorado também de forma contextualizada. Diante disso, o saneamento ambiental pode ser considerado um tema químico social no sentido mencionado por Santos e Schnetzler (2010), por possibilitar a contextualização do conteúdo e permitir o desenvolvimento de habilidades essenciais ao cidadão. Em relação aos temas químicos sociais os autores ressaltam que:

Ao contextualizar o conteúdo, os temas sociais explicitam o papel social da Química, as suas aplicações e implicações e demonstram como o cidadão pode aplicar o conhecimento na sua vida diária. Além disso, os temas têm o papel fundamental de desenvolver a capacidade de tomada de decisão, propiciando situações em que os alunos são estimulados a emitir opinião, propor soluções, avaliar custos e benefícios e tomar decisões, usando o juízo de valores. (SANTOS e SCHNETZLER, 2010, p.105).

A inserção de temas no conteúdo programático, de acordo com Santos e Schnetzler (2010), atende aos objetivos de que os estudantes compreendam os processos químicos do cotidiano, avaliem as implicações sociais das aplicações da química e compreendam a realidade social em que estão inseridos. Em suma, a adoção de temas é uma maneira reconhecida de articular os conhecimentos químicos ao contexto dos estudantes e de ampliar as possibilidades de discussão e até mesmo de intervenção.

De acordo com Beck (1997) apud Watanabe-Caramello e Strieder (2012), as discussões especialmente sobre questões que envolvem a interface ambiental, devem estar preocupadas em elucidar as relações envolvidas e não somente os resultados negativos 
herdados da geração passada, como poluição, degradação entre outros. Abordagens desse tipo podem contribuir de forma significativa para que as pessoas compreendam que atitudes localizadas podem influenciar no ciclo natural do planeta e repensem sua postura, responsabilizando-se pelas ações.

Em uma sociedade que se pretende democrática e participativa, os mecanismos de poder não podem permanecer de forma vertical. É preciso romper com o paradigma de que poucos são os que dispõem de condições, de conhecimento ou capacidade técnica para decidir as questões coletivas (ROUSLER e FABRIS, 2014). Nessa perspectiva sobressaem os ideais da Educação Ambiental crítica, que se contrapõe a modelos desenvolvimentistas que agravam a crise ambiental e aumentam a exclusão social (SANTOS et al., 2010).

Outra característica da Educação Ambiental crítica é a contraposição ao cientificismo e a separação da sociedade e natureza, propondo a transformação da realidade a partir da ação-reflexão e pelo aprender fazendo (SANTOS, et al., 2010). Inspirada nestas ideias-força que posicionam a educação imersa na vida, na história e nas questões urgentes do nosso tempo que a Educação Ambiental apresenta uma especificidade, que se refere à compreensão das relações sociedade-natureza e intervenção sobre problemas socioambientais (CARVALHO, 2004).

Dessa forma evita-se que propostas de ensino se reduzam ao que Tozoni-Reis (2004) considera como mero condicionamento de comportamentos com o propósito voltado exclusivamente para a conscientização dos sujeitos. Por isso, preza-se pela análise crítica e reflexiva dos problemas e à aquisição, mudança de atitudes e valores em relação ao ambiente.

O ensino articulado aos ideais da Educação Ambiental pode auxiliar na referida mudança e isso pode ser feito por meio da adoção de temas de relevância social, bem como a promoção de discussões que prezem pela formação de uma consciência crítica e participativa frente às situações da contemporaneidade. Partindo desse pressuposto, o presente artigo possui o objetivo de apresentar a análise de uma proposta que envolveu a abordagem de conceitos químicos por meio do tema saneamento ambiental.

\section{PROCEDIMENTOS INVESTIGATIVOS}

A proposta de abordagem de conceitos químicos por meio do tema saneamento ambiental foi elaborada no âmbito do Programa de Pós-Graduação em Ensino de Ciências da Universidade de Brasília (PPGEC/UnB), sendo desenvolvida em uma escola pública situada na cidade de Aparecida de Goiânia- Goiás. A aplicação envolveu a participação de 30 estudantes de idades (14 a 18 anos) e séries variadas ( $1^{\circ}, 2^{\circ}$ e $3^{\circ}$ ano) do Ensino Médio regular e a construção dos resultados ocorreu de forma articulada às aulas de uma disciplina eletiva. 
Ensino, Saúde e Ambiente - V13 (1), pp. 326-343, Abr. 2020

A disciplina mencionada faz parte do núcleo diversificado do modelo pedagógico dos Centros de Ensino em Período Integral que priorizam no conteúdo programático as principais dificuldades nas disciplinas de núcleo comum, tal como a química. São denominadas eletivas porque os estudantes podem eleger dentre as propostas ofertadas no semestre e se matricular na disciplina que pretendem cursar.

Os momentos de discussão realizados foram previamente autorizados, gravados e guiados por roteiros no contexto adaptado de grupo focal. A técnica de grupo focal foi adotada como instrumento de investigação devido às suas vantagens, apresentadas por Gondin (2003) como um tipo de entrevista coletiva que tem o potencial de promover à autorreflexão e a transformação social por estimular o pensamento crítico e participante, nesse caso dos estudantes diante do tema saneamento ambiental.

Com o intuito de avaliar o tipo de abordagem e os impactos das aulas, alguns questionamentos foram feitos, como: 1) Como você avalia o uso de temas como o saneamento ambiental para estudar conceitos químicos? 2) As discussões realizadas durante as aulas lhe trouxeram algum conhecimento novo? Se sim, qual(is)? 3) Qual a função social da química nas ações voltadas para o saneamento ambiental? 4) Para você os conceitos químicos têm alguma utilidade para a compreensão de problemas ambientais? Comente sobre o assunto.

O referencial adotado para a discussão dos resultados foi a análise de conteúdo de Bardin (1977). A análise consiste em um conjunto de técnicas que permite a inferência e interpretação dos resultados a propósito dos objetivos previstos ou que digam respeito a descobertas inesperadas. (BARDIN, 1977). A adoção desse tipo de análise deve-se ao foco atribuído à palavra dos sujeitos e suas significações, ou seja, a tentativa de conhecer o que está por trás das palavras, nesse caso áudios transcritos de falas dos estudantes durante as discussões realizadas nas aulas.

De posse dos resultados, Bardin (1977) orienta que é necessário determinar temas, categorias, unidades de registro (UR) e unidades de contexto (UC) para a elaboração das matrizes e discussão. A determinação dos elementos citados deve levar em conta os objetivos da pesquisa bem como os resultados construídos. Diante disso, o tema "ensino de química e tema saneamento ambiental" foi definido para a análise da proposta. Além disso, comentários feitos pelos estudantes durante as aulas foram transcritos e incluídos na discussão, contribuindo também para a análise da proposta.

\section{RESULTADOS E DISCUSSÃO}

A carga horária semanal destinada à disciplina de química é pequena e muitas vezes impulsiona o professor a desenvolver conceitos rapidamente pela exigência de contemplar 
conteúdos previstos para cada série. Mas uma possibilidade de lidar com a questão do tempo e propiciar discussões mais amplas em aulas de química é por meio da inserção de temas sociais no conteúdo programático. O ensino por meio de temas, segundo Santos e Schnetzler (2010), propicia a compreensão de processos químicos do cotidiano, avaliar implicações sociais das aplicações da química e entender a realidade em que os estudantes estão inseridos.

Os temas ambientais têm recebido grande enfoque em propostas educativas e isso pode ser um reflexo da preocupação com o agravamento de questões relacionadas ao ambiente em nível mundial e da necessidade de discutir sobre o assunto. Nesse sentido, o saneamento ambiental foi escolhido para ser abordado como um tema de relevância social nesta proposta, exatamente por possuir o potencial de promover discussões contextualizadas porque os serviços a ele relacionados ou a falta dele abarca a realidade das pessoas.

As 8 aulas que envolveram a abordagem de conceitos químicos por meio do tema saneamento ambiental foram totalmente conectadas com uma problemática local com o intuito de evitar um tratamento desligado de conceitos e de considerar o contexto ao qual os estudantes estavam inseridos. A problemática abrange uma unidade de conservação denominada Jardim Botânico de Goiânia/GO, localizada nas proximidades da escola e que se encontra degradada, conforme figura 1. A unidade possui remanescentes de mata seca e ciliar, espécies nativas do cerrado, animais silvestres e nascentes do córrego Botafogo, que possui relações com o saneamento da cidade.

O córrego Botafogo faz parte do contexto histórico de Goiânia, uma vez que a cidade foi construída às suas margens. $\mathrm{O}$ córrego é canalizado, conforme figura 2 e além das águas pluviais, Araújo e Pasqualetto (2007) mencionam que o córrego vem recebendo ao longo do seu percurso resíduos (líquidos e sólidos) derivados usos antrópicos existentes no entorno como floriculturas, atividades de lazer, serralheria, pavimentações, habitações irregulares e esgoto clandestino. Os usos mencionados afetam diretamente a qualidade das águas alterando assim seu equilíbrio ambiental.

Figura 1. Jardim Botânico (degradação)

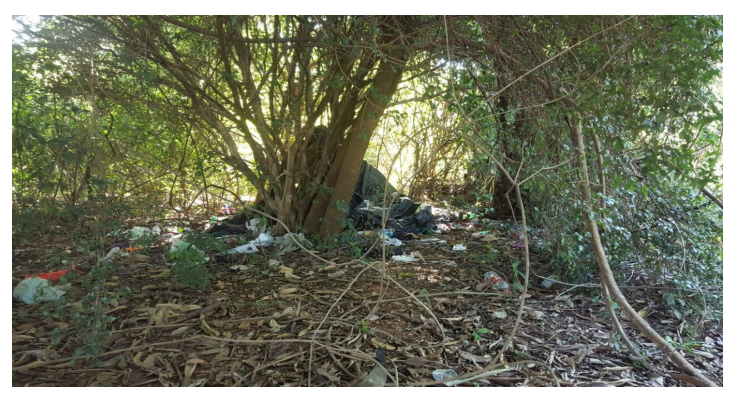

Fonte: Dados da Pesquisa.
Figura 2. Margens do córrego Botafogo

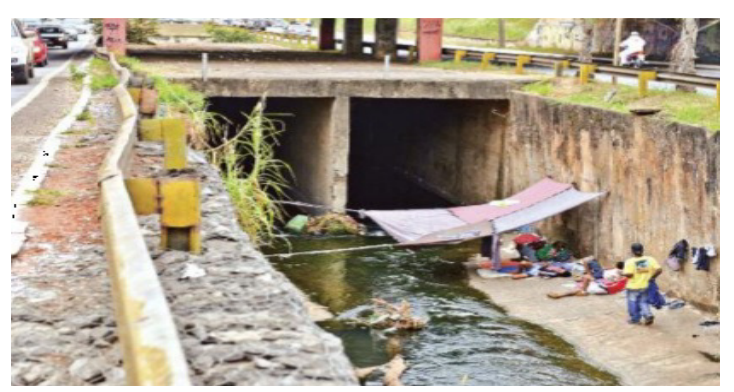

Fonte: Jornal O Hoje, Goiânia, p.1, 10 jul. 2015. 
Ensino, Saúde e Ambiente - V13 (1), pp. 326-343, Abr. 2020

Na sequência será apresentada uma breve descrição das aulas ressaltando os assuntos relacionados ao tema bem como os conceitos químicos explorados. A aula 1 denominada "(Re)conhecendo a problemática local e discussão sobre o saneamento" objetivou promover uma discussão inicial sobre o tema e principalmente a compreensão da problemática em suas múltiplas dimensões, mediados por saberes locais, além dos saberes científicos, no sentido mencionado por Carvalho (2004).

A aula 2, "Localização espacial e o atual foco nas questões do saneamento no Brasil", envolveu o uso de problemas detectados por meio da situação local para introduzir a discussão sobre o saneamento como tema manifesto no Brasil. Os resíduos sólidos jogados indevidamente no Jardim Botânico, sendo foco do Aedes aegypty, foi uma situação que impulsionou a discussão sobre a preocupação em nível nacional com locais que favorecem a proliferação do mosquito. A falta de saneamento foi discutida como um dos agravantes desse problema em algumas regiões do país.

Como aporte teórico para a discussão foram utilizadas reportagens expondo a preocupação com o assunto que tramitou em diversas instituições que compõem a sociedade, como o senado federal, a conferência nacional dos bispos do Brasil (CNBB) e o conselho nacional de igrejas cristãs (Conic). Estes últimos, segundo Verdélio (2016), lançaram o tema e o lema da campanha da fraternidade ecumênica de 2016, que alertou sobre o direito de todas as pessoas ao saneamento básico e debates de políticas públicas e ações que garantam a integridade e o futuro do meio ambiente.

Uma das contribuições do uso de reportagens é permitir que os estudantes se informem sobre assuntos atuais e façam associações, como demonstra a fala a seguir:

"Eu sou católica professora e ouvi mesmo o padre falando sobre a campanha da fraternidade e saneamento."

$\mathrm{Na}$ aula 3, chamada "Breve histórico do saneamento, visita virtual na ETE Goiânia e aplicações da química nesse contexto", foram discutidos os conceitos de saneamento básico e ambiental e as ações relacionadas, como o tratamento de água e esgoto, manejo de resíduos sólidos e de águas pluviais.

Uma linha do tempo do saneamento foi estudada, destacando acontecimentos da antiguidade relacionados a falta de saneamento, as primeiras grandes obras e inovações tecnológicas nessa área, como o atual modo de tratamento de esgoto. Em seguida foi apresentada uma inovação relacionada com o saneamento ambiental, exemplificada por meio da visita virtual na Estação de Tratamento de Esgoto (ETE) Dr. Hélio Seixo de Britto, localizada em Goiânia - Goiás. A figura 3 refere-se a parte inicial da simulação que apresentava de modo geral as etapas do tratamento de esgoto. 
Ensino, Saúde e Ambiente - V13 (1), pp. 326-343, Abr. 2020

Figura 3. Parte inicial da visita virtual na ETE Goiânia ${ }^{1}$

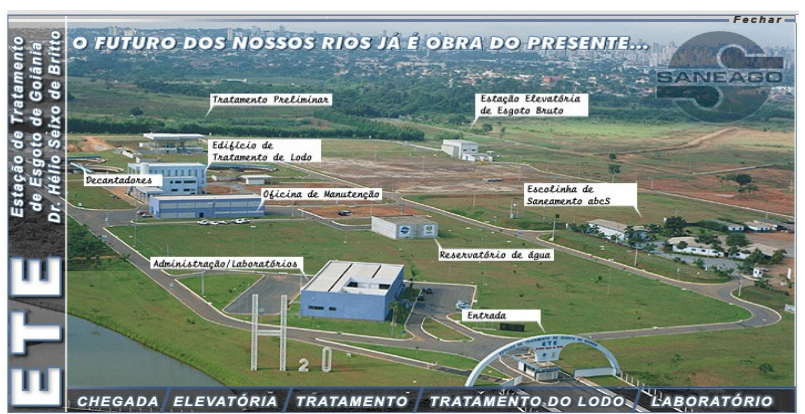

Com isso os estudantes reconheceram os avanços em benefício das pessoas, conforme demonstra a fala a seguir:

"Nossa! Nunca ouvi falar nisso. Fico pensando que a ciência e a tecnologia avançaram demais e os benefícios são muitos né."

Além de atentar para o funcionamento da ETE, os estudantes foram instruídos a identificar termos que se relacionavam de alguma forma com a química. A partir dos termos elencados como sulfato de alumínio, coagulantes, decantação etc. puderam ser explorados os conceitos de substâncias químicas e métodos de separação de misturas.

Desse modo é caracterizado o ensino de química para a formar o cidadão, defendido por Santos e Schnetzler (2010), pois houve a preocupação de não restringir o ensino à mera discussão ideológica do contexto social nem ao estudo de conceitos químicos descontextualizados, como se fossem puros e neutros. A simulação como estratégia de ensino apresentou-se como uma maneira diversificada da prática escolar e uma forma eficiente de promover a contextualização. A fala a seguir merece destaque:

“Então, esse negócio ai de simulação é legal né, porque mesmo não podendo ir lá na ETE conhecemos como é feito o tratamento do esgoto em Goiânia."

A aula 4, denominada “Trilhas, museu, jardim sensorial e coleta de água da nascente do córrego Botafogo no Jardim Botânico", envolveu a abordagem dos conceitos de análise físico-química e biológica da água, diferença entre análise quantitativa e qualitativa, amostragem, aferição de temperatura e medida de potencial hidrogeniônico $(\mathrm{pH})$ in situ. A aula foi comentada pelos estudantes:

"É interessante porque nós mesmos fizemos a coleta e as análises no lugar da nascente e como você disse, o resultado é melhor né."

$\mathrm{Na}$ aula 5, "Normas de segurança de laboratório e análises de amostras de água do córrego Botafogo", as medições feitas in situ foram repetidas e a cor das amostras foi

\footnotetext{
${ }^{1}$ A fonte não foi citada pois o site da SANEAGO (empresa responsável pelo abastecimento de água da cidade) foi atualizado e a visita não está mais disponível. 
analisada. Por ser uma aula no laboratório de ciências foram apresentadas as normas de segurança e pictogramas. Como a análise de $\mathrm{pH}$ foi feita com indicador ácido-base foi necessário explorar seu conceito, bem como o de escala de pH. Além disso, a diferença entre poluição e contaminação também foi estudada com o intuito de introduzir o conteúdo da próxima aula, denominada "Quimicamente falando sobre parâmetros da qualidade da água e manejo de resíduos sólidos."

A aula 6 envolveu a abordagem dos parâmetros da qualidade da água, especialmente em relação aos metais pesados. Os estudantes chegaram a algumas conclusões, tais como: "Entendi que o fato da água estar limpa não significa que não está contaminada, para saber se
existe contaminação é preciso fazer análises em laboratórios."

Nas aulas 4, 5 e 6 os conceitos foram relacionados com o saneamento sob a justificativa de que tanto a água quanto o esgoto passam por um tratamento que envolve uma série de etapas e análises físico-químicas e biológicas obedecendo parâmetros definidos pela literatura que asseguram a qualidade e a potabilidade.

Ainda sobre a aula 6, outra ação relacionada ao saneamento ambiental foi abordada: o manejo de resíduos sólidos. A diferença entre lixão e aterro sanitário foi explicada de modo que o enfoque se baseou no chorume, sua composição química e impactos no ambiente. Outros tipos de destinação final foram estudados, tais como: compostagem e incineração sendo explorados os conceitos de matéria orgânica, processos endotérmicos e exotérmicos etc. Por fim, a apresentação dos 3' Rs (redução, reutilização e reciclagem) teve como objetivo esclarecer a diferença entre eles e abordar os conceitos de transformação física e química, respectivamente.

A todo momento buscou-se realçar a função social da química com a perspectiva de que os estudantes atribuam significados, ou seja, se apropriem de razões que justifiquem o estudo de informações e/ou conceitos químicos. Dentre as razões, destacou-se o desenvolvimento da química com a busca de soluções para problemas ambientais e o tratamento de doenças por meio de pesquisas em suas subáreas, como na Química Verde e Química de Produtos Naturais.

$\mathrm{Na}$ aula 7, denominada "A química no contexto do saneamento ambiental: em foco o tratamento de água", foram abordados os conceitos de sedimentação, floculação, filtração e desinfecção como processos envolvidos nesse tratamento. Também foram realizados experimentos com amostras de água do córrego Botafogo na tentativa de exemplificar alguns dos processos estudados. Além disso, a biografia do médico e sanitarista Oswaldo Cruz (1872 - 1917) foi discutida. Considerado o fundador da saúde pública no Brasil, ele defendeu a tese de doutorado "Veiculação microbiana pelas águas" e posteriormente na condição de diretor 
Ensino, Saúde e Ambiente - V13 (1), pp. 326-343, Abr. 2020

geral de saúde pública, hoje cargo correspondente ao ministro da saúde, promoveu memoráveis campanhas de saneamento.

O mapa do saneamento no Brasil, que apresenta informações sobre a rede de coleta de esgoto e água tratada também foi comentado durante a aula, conforme figura 4 . O objetivo consistiu em apresentar a realidade em termos percentuais da população urbana atendida pelas redes mencionadas, o que leva à alarmante constatação de que muitos brasileiros ainda não têm acesso à água tratada e rede de coleta de esgoto.

Figura 4. Mapas do saneamento no Brasil (adaptado)

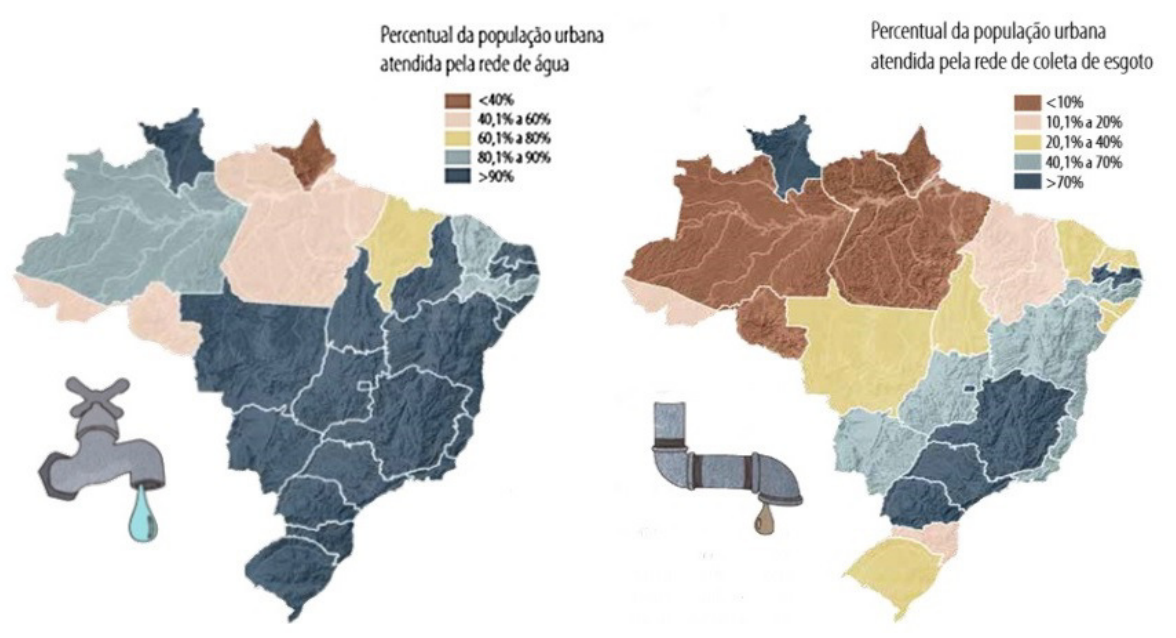

Fonte: Revista Em Discussão!, Brasília, n. 27, mai. 2016.

Por fim a aula 8, denominada "Meio ambiente, plástico e polímeros", buscou apresentar uma breve retrospectiva em relação ao tipo de material utilizado para embalar objetos ao longo do tempo até a invenção do plástico. A aula se fez necessária pois a maioria dos resíduos sólidos jogados de forma indevida no Jardim Botânico eram provenientes desse material. Foram discutidos também os pontos positivos e negativos do uso do plástico, a relação custo-benefício e os impactos no ambiente.

Quimicamente, foram abordados os conceitos de polímeros, massa molar desse material, cadeias poliméricas, símbolos da reciclagem para plástico e nomenclatura dos mais comuns, por exemplo: politereftalato de etileno (PET) e policloreto de vinila (PVC). Foi discutido também o avanço no desenvolvimento dos polímeros que levou ao surgimento de uma subárea da química, chamada: Química dos Materiais.

Um dos objetivos das aulas consistiu em mostrar para os estudantes a dependência da sociedade em relação a química e a sua relação com o saneamento. Dependência que segundo Santos e Schnetzler (2010), vai desde a utilização diária de produtos químicos até as mais variadas influências e impactos no desenvolvimento do país, em problemas referentes à 
qualidade de vida das pessoas, nos efeitos ambientais das aplicações tecnológicas e nas decisões solicitadas aos indivíduos sobre o uso dessas tecnologias.

Com o intuito de avaliar os impactos das aulas, alguns questionamentos foram feitos aos estudantes e as respostas foram organizadas na matriz de análise da tabela 1.

Tabela 1. Matriz de análise sobre a abordagem de conceitos químicos por meio do tema.

\begin{tabular}{|c|c|c|c|}
\hline Tema & Categoria & Unid ades de Registro (UR) & Unidades de Contexto (UC) \\
\hline \multirow{4}{*}{ 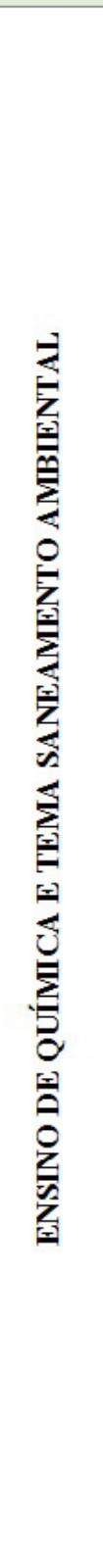 } & \multirow[t]{2}{*}{ Tema } & Relação & $\begin{array}{l}\text { "Estabelece um equilíbrio né entre si, os temas } \\
\text { e os conceitos. Eu achei interessante!" } \\
\text { "Eles ligam entre si e isso é positivo, facilita a } \\
\text { aprendizagem." } \\
\text { "A matéria é bem disseminada por meio do } \\
\text { tema." } \\
\text { "É óbvio porque já é algo essencial que é o } \\
\text { saneamento e o uso da química e tira proveito } \\
\text { disso para um benefício maior que é aprender os } \\
\text { conceitos." }\end{array}$ \\
\hline & & Aplicação & $\begin{array}{l}\text { "É importante, porque assim a gente sabe que } \\
\text { tem uma aplicação da ciência, nesse caso para a } \\
\text { química. Porque um precisa do outro." } \\
\text { "Aprendi sobre o descarte de materiais, aterro e } \\
\text { lixão, reciclagem e reutilização." } \\
\text { "Como funciona a estação de tratamento de } \\
\text { água e a de esgoto, importância." }\end{array}$ \\
\hline & \multirow[b]{2}{*}{$\begin{array}{l}\text { Conceitos } \\
\text { Químicos }\end{array}$} & Agregação & $\begin{array}{l}\text { "Sou do primeiro ano e não conhecia o conceito } \\
\text { de pH, tinha ouvido falar mas a explicação não." } \\
\text { "Eu não sabia o quanto é importante conhecer a } \\
\text { linguagem química. Por exemplo aquela se } \\
\text { pegar um béquer e colocar areia e água, você } \\
\text { tem que saber o conceito de densidade, porque } \\
\text { cxistcm si tuaçõcs no dia a dia rclacionadas." } \\
\text { "Conheci um pouco sobre os processos } \\
\text { químicos do tratamento de água e esgoto." } \\
\text { "Algumas fórmulas químicas." }\end{array}$ \\
\hline & & Utilidade & $\begin{array}{l}\text { "Tem processos que degradam o meio ambiente } \\
\text { e a química pode ajudar a achar meios de } \\
\text { diminuir esses impactos." } \\
\text { "Muita importância, até mesmo no processo de } \\
\text { composição e decomposição precisa de } \\
\text { química. Tudo no ambiente é química." } \\
\text { "Existe até a química verde, ela ajuda o } \\
\text { ambiente encontrando meios que evitam a } \\
\text { poluição, contaminação e degradação." } \\
\text { "A água é uma substância química que constitui } \\
\text { maior parte do corpo humano e uma aplicação } \\
\text { no tratamento de água é importante para nossa } \\
\text { saúde. } \\
\text { "Sem a química não teriam os reagentes e } \\
\text { processos para tornar a água potável." }\end{array}$ \\
\hline
\end{tabular}

Fonte: Grupo focal adaptado.

As respostas permitem inferir que os estudantes perceberam o propósito da abordagem realizada nas aulas, que visou estabelecer relações entre os conceitos químicos e o tema saneamento ambiental. A forma com que os conceitos foram diluídos, de acordo com o desenvolvimento das discussões relacionadas ao tema saneamento, foi comentada como um fator positivo. Diante disso, anima-nos distanciar de propostas como as mencionadas por 
Morin (2011) que tendem a afastar as ciências dos indivíduos, apresentando disciplinas hiperespecializadas e sobretudo fechadas em si mesmas, impossibilitando a realização de conexões com outros conhecimentos.

De acordo com Hissa (2008) os saberes ambientais, como os estudados por meio da problemática local, são constituídos de matérias cortantes que atravessam e habitam fronteiras e aponta também a necessidade de abertura para além das disciplinas, pois as fronteiras indicam que muito mais do essencial está além dos territórios convencionais. Partindo desse pressuposto que esta proposta de ensino buscou estabelecer o diálogo de saberes e a mediação com o mundo defendidos por Freire (1987) e Hissa (2008).

É importante ressaltar também que os estudantes consideraram a relevância de discussões sobre as aplicações da química e indicaram o potencial delas para a aprendizagem. $\mathrm{O}$ argumento a seguir exemplifica essa afirmação. Além disso, a agregação de conceitos e aprimoramento de conhecimentos foi outro fator destacado.

"É óbvio porque já é algo essencial, que é o saneamento e o uso da química, e tira proveito disso para um benefício maior que é aprender os conceitos."

A linguagem química também foi trabalhada de forma simultânea às aulas partindo do pressuposto descrito por Santos e Schnetzler (2010) ao mencionar que é interessante que o cidadão tenha tais conhecimentos para o seu enriquecimento cultural, sabendo, por exemplo, que o nylon, uma das fibras sintéticas de nossas roupas, é uma poliamida; que os componentes de materiais protetores, como vernizes e tintas, são polímeros; que os antibióticos, conhecidos como sulfas, são sulfamidas entre outros.

Por fim, os estudantes foram questionados quanto a utilidade dos conceitos químicos para compreender e resolver problemas ambientais e vários exemplos foram citados, principalmente em se tratando da atuação da química em prol da melhoria dos problemas mencionados. Destacaram-se as falas a seguir, onde novamente a função social da química foi ressaltada bem como a sua presença em tudo que nos cerca.

\footnotetext{
“Tem muita importância, até mesmo no processo de composição e decomposição precisa de química. Tudo que contém no ambiente é química. A química é diretamente ligada com o ambiente."

"Existe até a química verde, ela ajuda o meio ambiente encontrando meios que evitam a poluição, contaminação e degradação."
}

A análise global da abordagem de conceitos químicos por meio do tema saneamento ambiental permite caracterizá-la como proveitosa, por propiciar tanto a aprofundamento e agregação de conceitos e valores, quanto o estímulo ao posicionamento crítico diante das 
Ensino, Saúde e Ambiente - V13 (1), pp. 326-343, Abr. 2020

situações. Seguimos as orientações de Santos e Schnetzler (2010) ao mencionar que os temas não devem ser considerados como mais um elemento a ser incluído no conteúdo programático, mas sim como um poderoso mecanismo para auxiliar na formação cidadã.

As discussões e especialmente a aula que envolveu o contato direto dos estudantes com a problemática local desencadeou a reflexão sobre a degradação ambiental e consequentemente a busca por maiores informações e até mesmo possíveis soluções para os problemas detectados, sendo esta uma premissa da Educação Ambiental crítica, conforme mencionado por Carvalho (2004). A situação pode ser explicada também por meio dos apontamentos de Monteiro Silva e Tavares (2012) ao dizer que os adolescentes, como os envolvidos nesta proposta, são agregadores e possuem a necessidade de estabelecer relações de organização e convivência.

O estudo de uma problemática local pode desenvolver o sentimento de pertencimento e identidade com a escola, com a comunidade e a inclusão dos participantes na condição de ser humano, partícipe de projetos da sociedade e corresponsável pelo ambiente em que está inserido, conforme mencionam Monteiro Silva e Tavares (2012).

\section{CONCLUSÃO}

A proposta analisada e apresentada neste artigo partiu do pressuposto de que a ciência, nesse caso a química, deve estar ao alcance da interpretação e questionamento dos indivíduos, sendo esse um dos motivos pelos quais foram apresentados não somente os conceitos químicos, mas também aplicações no contexto do saneamento ambiental. Desse modo pode ser incentivada a compreensão de processos químicos, como no tratamento de água e/ou esgoto, reciclagem etc. que se relacionam de alguma forma com o cotidiano dos estudantes.

Mesmo que o cotidiano de alguns estudantes não abarque os serviços relacionados ao saneamento como a rede de coleta de esgoto e de água torna-se relevante a discussão dos porquês da situação bem como os direitos do cidadão em se tratando de saneamento. $\mathrm{O}$ conhecimento nesse caso, sobressai como meio de interpretar o mundo e como fundamentação para o posicionamento frente as mazelas da sociedade contemporânea.

Diante dos resultados referentes à aplicação da proposta é possível afirmar que a abordagem contextualizada dos conceitos químicos por meio de temas, como o saneamento ambiental, possui potencial formativo e ainda se distancia do ensino baseado na mera memorização de nomes e fórmulas. A inserção de temas sociais como o saneamento ambiental em aulas de química pode propiciar tanto a agregação de conceitos quanto auxiliar na formação de uma consciência crítica e participativa dos estudantes diante de situações socioambientais tanto no contexto local quanto global. 
Ensino, Saúde e Ambiente - V13 (1), pp. 326-343, Abr. 2020

\section{REFERÊNCIAS}

ARAÚJO, D.P.; PASQUALETTO, A. Análise de risco às águas superficiais do córrego Botafogo. Goiânia, Goiás, 2007, 23p. Trabalho de Conclusão de Curso - Graduação em Engenharia Ambiental - Pontifícia Universidade Católica de Goiás.

BARDIN, L. Análise de Conteúdo. Tradução de Luís Antero Reto e Augusto Pinheiro. São Paulo: Edições 70, 1977.

BRANCO, S.M. Poluição: a morte de nossos rios. Rio de Janeiro: Livro técnico, 1972.

BRASIL. Ministério das Cidades. Organização Pan-Americana da Saúde. Política e plano municipal de saneamento ambiental: experiências e recomendações. Programa de Modernização do Setor de Saneamento. Brasília: OPAS, 2005.

CARVALHO, I.C.M. Educação Ambiental Crítica: nomes e endereçamentos da educação. In: LAYRARGUES, P.P. Identidades da Educação Ambiental Brasileira. Brasília: MMA, 2004.

FREIRE, P. Pedagogia do oprimido. $17^{\circ}$ ed. Rio de Janeiro: Paz e Terra, 1987.

GONDIN, S. M. G. Grupos focais como técnica de investigação qualitativa: desafios metodológicos. Paidéia - Cadernos de Psicologia e Educação, v.12, n.24, p.149-161, 2003.

HISSA, C.E.V. Saberes Ambientais: desafios para o conhecimento disciplinar. Belo Horizonte: UFMG, 2008.

LEAL, A.L. Relações entre Saneamento - Química - Meio Ambiente na Educação Profissional e Tecnológica numa Perspectiva Crítico-Transformadora. Tese de doutorado, UFSC, 2012.

MONTEIRO SIlVA, A.; TAVARES, C. A formação cidadã no Ensino Médio. Coleção educação em direitos humanos, v.2 São Paulo: Cortez, 2012.

MORIN, E. Os sete saberes necessários à educação do futuro. $2^{\circ}$ ed. São Paulo: Cortez; Brasília, DF: UNESCO, 2011.

PINHÃO, F.; MARTINS, I. Diferentes abordagens sobre o tema saúde e ambiente: desafios para o Ensino de Ciências. Ciência \& Educação, v.18, n.4, p. 819-835, 2012.

REZENDE, S.C.; HELLER. O saneamento no Brasil: políticas e interfaces. 2.ed. rev. e ampl. Belo Horizonte: Editora UFMG, 2008.

ROCHA, A.A. Fatos históricos do saneamento. São Paulo: Scortecci, 1997.

ROESLER, M.R.V.B.; FABRIS, D.R. Saúde Ambiental e Educação Ambiental: interlocução rompendo paradigmas. Rev. Eletrônica do Mestrado em Educação Ambiental, v. especial, Mai, p.109-120, 2014.

SANTOS, W.L.P.; GALIAZZI, M.C.; PINHEIRO JUNIOR, E.M.; SOUZA, M.L.; PORTUGAL, S. O Enfoque CTS e a Educação Ambiental: Possibilidade de 
Ensino, Saúde e Ambiente - V13 (1), pp. 326-343, Abr. 2020

"ambientalização" da sala de aula de Ciências. In: SANTOS, W.L.P.; MALDANER, O. A. (Orgs). Ensino de química em foco. Unijuí, Ijuí, 2010.

SANTOS, W.L.P.; SCHNETZLER, R.P. Educação em química: compromisso com a cidadania. 4 ed. Ijuí: Editora da Unijuí, 2010.

SENADO FEDERAL. Saneamento: a linha divisória da saúde pública. Revista Em Discussão! [online] Brasília, n. 27, mai. 2016. Disponível em: < http://www12.senado.leg.br/emdiscussao/edicoes/saneamento-basico.> Acesso em 11 Abr. 2017.

SILVA, D.F.; MOREJON, C.F.M.; LESS, F.R. Prospecção do panorama do saneamento rural e urbano no Brasil. Rev. eletrônica do Mestrado em Educação Ambiental, v. especial, Mai, p.245-257, 2014.

TOZONI-REIS, M.F. Educação ambiental: natureza, razão e história. Campinas: Ed. Autores Associados, 2004.

VERDÉLIO, A. 2016. Campanha da Fraternidade alerta para necessidade de saneamento básico no Brasil. Disponível em:

$<$ http://www.ecodesenvolvimento.org/posts/2016/posts/fevereiro/campanha-da-fraternidadealerta-para-necessidade?tag=eventos-sustentaveis $>$. Acesso em 11 Abr. 2017.

WATANABE-CARAMELLO, G.; STRIEDER, R.B. Elementos para inserir questões ambientais em aulas de física: da prática baseada em temas à complexificação do conhecimento. Pesquisa em Educação Ambiental, v. 6, n. 2, p. 101-117, 2011.

\section{SOBRE OS AUTORES}

\section{AUTOR 1.}

Graduada em Química pela Pontifícia Universidade Católica de Goiás (2014), Especialista em Métodos e Técnicas de Ensino pela Faculdade Brasileira de Educação e Cultura (2016), Mestra em Ensino de Ciências pela Universidade de Brasília (PPGEC/UnB - 2017), tendo defendido a dissertação denominada "Química e Saneamento Ambiental: uma proposta contextualizada de ensino", cujo recorte dos resultados estão apresentados no presente artigo. É doutoranda vinculada ao Programa de Pós-Graduação em Educação e Ciências e Matemática da Universidade Federal de Goiás e professora no Centro Universitário UniAraguaia, ministrando disciplinas relacionadas à Química e Bioquímica. Atua principalmente nas seguintes linhas de pesquisa: Educação Ambiental, Ensino de Química e/ou Ciências e Formação de Professores.

\section{AUTOR 2.}

Graduada em Farmácia e Bioquímica pela Universidade de São Paulo (1979), Mestra em Ciências Biológicas pela Universidade de São Paulo (1983) e Doutora em Microbiologia e Imunologia pela Universidade de São Paulo (1989). A pesquisa de doutorado envolveu protozoário tripanosomatídeo (Crithidia fasciculata), tendo participado de diversos congressos e simpósios voltados a Doença de Chagas e outras endemias. Foi professora na Universidade de Brasília da disciplina de Microbiologia ofertada para Biologia e diversos cursos da área de Saúde de 1985 a 2019, atualmente aposentada. Desenvolveu a metodologia interdisciplinar da "Educação Ambiental Sustentável", na que se formaram centenas de professores da Educação 
Básica. É professora e orientadora do Programa de Pós-Graduação em Ensino de Ciências (PPGEC-UnB) nas seguintes linhas de pesquisa: educação ambiental, ensino de ciências, educação a distância, formação de professores. Atua também na área de Bioética e desde 2017 é membro do Conselho Nacional de Saúde (CNS), como representante de usuário, e no âmbito do CNS é coordenadora adjunta da Comissão de Ciência e Tecnologia e Assistência Farmacêutica, e membro da Comissão Intersetorial de saúde das mulheres. 